\title{
Adriana Sfragaro, Poetesse romantiche francesi. Antologia con testo a fronte
}

\section{Laura Colombo}

\section{(2) OpenEdition}

1 Journals

\section{Édition électronique}

URL : http://journals.openedition.org/studifrancesi/30398

DOI : 10.4000/studifrancesi.30398

ISSN : 2421-5856

Éditeur

Rosenberg \& Sellier

\section{Édition imprimée}

Date de publication : 1 avril 2006

Pagination : 164-165

ISSN : 0039-2944

\section{Référence électronique}

Laura Colombo, «Adriana Sfragaro, Poetesse romantiche francesi. Antologia con testo a fronte », Studi Francesi [En ligne], 148 (XLX | I) | 2006, mis en ligne le 30 novembre 2015, consulté le 19 avril 2021. URL : http://journals.openedition.org/studifrancesi/30398; DOI : https://doi.org/10.4000/ studifrancesi.30398

Ce document a été généré automatiquement le 19 avril 2021.

\section{(c)}

Studi Francesi è distribuita con Licenza Creative Commons Attribuzione - Non commerciale - Non opere derivate 4.0 Internazionale. 


\title{
Adriana Sfragaro, Poetesse romantiche francesi. Antologia con testo a fronte
}

\author{
Laura Colombo
}

\section{RÉFÉRENCE}

ADRIANA SFRAGARO, Poetesse romantiche francesi. Antologia con testo a fronte, trad. di Adriana Sfragaro, Firenze, Aletheia, 2003 ( « Scaffale romantico / Testi »), pp. 164.

1 Depuis quelques années, le Centro Interdisciplinare di Studi Romantici de l'Université de Bologne a entamé une importante initiative de recherche sur l'écriture féminine du XIXe siècle au niveau européen, dont ce volume est l'un des fruits. Profitant des résultats de la critique féministe de ces dernières années et continuant notamment, dans ce domaine, l'œuvre de Jeanine Moulin ou Christine Planté, ce volume est le premier, en Italie, consacré à des femmes poètes encore méconnues.

Oubli, silence et richesse des voix : ce sont là les mots-clés de cette étude, qui se donne le but de réparer et combler l'oubli de la critique et de l'édition, en redonnant « spazio e visibilità » (p.10) à la pluralité de la production poétique féminine du XIX ${ }^{\mathrm{e}}$ siècle. La recherche, qui n'exclut aucunement la dimension historique et plonge ses racines dans le $\mathrm{XVIII}^{\mathrm{e}}$ siècle, décèle avant tout les intentions de cette écriture poétique, épanchement lyrique, mais aussi instrument de «libertà e affermazione di sé » (p. 18). L'anthologie est divisée en trois sections - la poésie douloureuse, la poésie ouvrière et la poésie féministe - qui offrent un panorama de la variété et de la richesse des gestes créateurs. Les sections, les auteures et les oeuvres sont présentées avec une documentation très riche et un jugement sûr. Quant aux noms, les plus cités, Amable Tastu, Constance de Salm, Anaïs Ségalas Élisa Mercoeur ou Adélaïde Dufrenoy, côtoient les moins connus, comme Victoire Babois, Marie-Laure Grouard, Marie PapeCarpantier. 
3 La poésie de la maternité est l'une des spécificités évidentes de ces femmes, et l'idée est insolite, mais intéressante, de choisir non pas Marceline Desbordes-Valmore, la voix la plus connue du courant romantique féminin, mais plutôt sa fille, Ondine, objet habituel de la poésie de sa mère qui redevient en l'occurrence sujet, avec sa production entre 1830 et 48. Une autre fille, Bertile, futur écrivain elle aussi, est évoquée par Anaïs Ségalas, auteur entre autres d'un poème sur les femmes artistes. Les thèmes qui ressortent de cette anthologie entérinent en effet une richesse qui va bien au-delà des attentes: à côté de l'effusion sentimentale (voir p.11), qui s'avère parfois originale, lorsque par exemple elle n'imite pas mais anticipe certains caractères du Romantisme, pour la tonalité douloureuse de certaine attitude psychologique féminine, à côté des thèmes élégiaques, de la poésie de la nature ou de circonstance, le vers est parcouru par des débats sur l'actualité, le divorce entre autres, mais aussi sur les problèmes d'esthétique, sur la "gloire» et la présence dans le monde «public», en approfondissant une analyse de la condition féminine qui envahit tous les sous-genres.

4 Outre la bibliographie primaire, utile rappel des oeuvres principales des poétesses étudiées, la bibliographie secondaire institue un bilan de la critique, qui parfois met en évidence une pénurie qui ne saurait dépasser des oeuvres collectives, des nécrologies, des courts articles, mais de l'autre côté indique la persistance d'un intérêt qui justifie aujourd'hui un approfondissement de la recherche et de l'analyse.

5 En constatant donc l'importance, au niveau italien et international, de cette étudeanthologie, nous n'avons qu'à espérer que l'auteur veuille nous offrir d'autres résultats de ses précieuses recherches. 